\title{
Métodos de enxertia na produção de mudas de tamarindeiro
}

\author{
Glêidson Bezerra de Góes ${ }^{2}$ Isabel Giovanna Costa e Melo ${ }^{3}$, Vander Mendonça ${ }^{4 *}$ \\ Django Jesus Dantas ${ }^{5}$, Grazianny Andrade Leite ${ }^{6}$
}

$10.1590 / 0034-737 X 201663060015$

\section{RESUMO}

O tamarindo (Tamarindus indica L.) vem despertando interesse da população sul-americana por suas propriedades medicinais. Contudo, estudos com técnicas agronômicas para a espécie são ainda escassos. Com o objetivo de determinar o melhor método de enxertia para a produção de mudas de tamarindeiro, foi realizado um experimento em casa de vegetação na Universidade Federal Rural do Semi-Árido - UFERSA, em Mossoró, RN. O delineamento utilizado foi o de blocos casualizados, constituído por cinco tratamentos, que foram os métodos de enxertia (garfagem no topo em fenda cheia, garfagem no topo à inglesa, simples, garfagem no topo à inglesa, complicada, garfagem em fenda lateral e borbulhia em placa), com sete repetições, sendo cada parcela composta por 14 mudas. Foram avaliados: percentagem de pegamento dos enxertos, comprimento da parte aérea, comprimento do sistema radicular, comprimento de ramos, número de folhas, número de ramos, diâmetro do colo, matéria seca da parte aérea, matéria seca do sistema radicular, matéria seca total. Os dados obtidos foram submetidos à análise de variância e comparados pelo teste Tukey, a 5\% de significância. Garfagem no topo em fenda cheia, garfagem no topo à inglesa complicada e garfagem no topo à inglesa simples foram os melhores métodos de enxertia para o tamarindeiro.

Palavras-chave: fruticultura exótica; família leguminosae; qualidade de mudas.

\section{ABSTRACT}

\section{Grafting methods for production of tamarind (Tamarindus indica L.) seedlings}

The tamarind (Tamarindus indica L.) is attracting interest of the South American population due to its medicinal properties. However, studies with agronomic techniques for the species are scarce. Aiming to determine the best grafting method for the production of tamarind seedlings, an experiment was conducted in the greenhouse at the Universidade Federal Rural do Semiárido - UFERSA, Mossoró, RN. The design used was a completely randomized blocks, consisting of five grafting methods (top cleft grafting, English top cleft grafting, top grafting "complicated English way", side cleft grafting, and plate budding) with seven replicates and each plot with 14 plant seedlings. The variables evaluated were: percentage of grafting success, shoot length, root length, branch length, leaf number, branch number, stem diameter, shoot dry matter, root dry matter, and total dry matter. The data were subjected to analysis of variance and compared by Tukey test at 5\% significance. The methods top cleft grafting, top grafting "complicated English way", and English top grafting are, respectively, the best grafting methods for the tamarind.

Key words: exotic fruit growing; family leguminosae; seedling quality. 


\section{INTRODUÇÃO}

$\mathrm{O}$ tamarindeiro (Tamarindus indica $\mathrm{L}$.) pertence à família das fabáceas, subfamília Caesalpinoideae, sendo originário da África Tropical, de onde se dispersou. É encontrado em várias regiões brasileiras, adaptado aos diversos estados, e plantado dispersadamente, sendo considerado fruto típico (Sousa et al., 2010). Os indivíduos que crescem nos trópicos derivam de sementes coletadas, ao acaso, na África e na Índia, as quais são, portanto, destituídas de melhoramento genético. Ainda assim, o tamarindeiro desponta como cultura atrativa e de grande futuro comercial (Seagri, 2010).

Entre as frutíferas tropicais exóticas, o tamarindo destaca-se por apresentar excelentes qualidades nutricionais. Pelo seu agradável aroma e sabor ácido-doce, o fruto é muito utilizado na fabricação de refrescos, sorvetes, pastas, doces, licores, geleias e também como ingrediente em condimentos e molhos (Gurjão, 2006). Praticamente, todas as partes da planta possuem utilidade na medicina popular, e apresentam inúmeras aplicações terapêuticas em humanos, dentre elas o uso como digestivo, calmante, laxante, expectorante e tônico sanguíneo (Komutarin et al., 2004). Diversos estudos apontam atividades farmacológicas da espécie, dentre estas, anti-inflamatória e analgésica (Suralkar et al., 2012).

No entanto, apesar do crescente interesse pela cultura, poucos estudos abordam aspectos relacionados com a propagação do tamarindeiro, mencionando-se que esta ocorre, sexuadamente, por sementes e, vegetativamente, por enxertia, estaquia e alporquia, porém com predominância da via sexuada (El-Siddig et al., 2006), o que provoca grande variabilidade nas plantas e nos frutos, ocorrência de árvores com vigor excessivo e maior altura, retardamento da produção (por causa do longo período improdutivo causado pela juvenilidade), além de produtividade irregular, colheita difícil, demorada e de elevado custo.

Considerando-se a potencialidade do tamarindeiro no nordeste brasileiro, informações técnicas seguras, que definam uma forma assexuada de propagação, são de suma importância, já que favorecerão a perpetuação de características superiores e uniformidade da produção. Diante disso, objetivou-se, com este trabalho, testar diferentes métodos de enxertia na produção de mudas de tamarindeiro, visando à produção de mudas com qualidade.

\section{MATERIAL E MÉTODOS}

$\mathrm{O}$ experimento foi instalado e conduzido em casa de vegetação com cobertura de sombrite, com passagem de $50 \%$ de luminosidade, localizada na Universidade Federal Rural do Semi-Árido (UFERSA), situada na cidade de Mossoró, RN, de janeiro de 2009 a junho de 2010.
As sementes utilizadas para produção dos portasenxerto foram provenientes de frutos de uma única planta adulta, situada no campus da UFERSA, na safra de 2008. Os frutos foram despolpados manualmente e as sementes passaram pelo procedimento de lavagem em água corrente, para a retirada de restos de polpa. Em seguida, foram postas para secar, à sombra, sob jornal, por um período de 24 horas. Foram semeadas, na profundidade média de $2 \mathrm{~cm}$, três sementes por saco de polietileno, cada saco tinha capacidade de 2,5 litros, e continha substrato com proporção $2: 1$ (v/v) de solo e esterco bovino. Fertilizou-se o solo com superfosfato simples e cloreto de potássio, nas dosagens $10 \mathrm{~kg} \mathrm{~m}^{-3}$ e 2,0 $\mathrm{kg} \mathrm{m}^{-3}$, respectivamente. Quando as mudas atingiram cerca de 5 $\mathrm{cm}$ de altura, foi realizado o desbaste, cortando-se as mudas com auxílio de uma tesoura, deixando-se apenas uma por recipiente.

As mudas foram enxertadas quando apresentaram diâmetro de colo com aproximadamente $5 \mathrm{~mm}$, dez meses após a semeadura. Os garfos e as borbulhas foram coletados em planta matriz situada no Campus Central da UFERSA. Os garfos empregados na enxertia foram obtidos de planta adulta, sadia e vigorosa, com 12 anos de idade; colhidos na periferia da copa da planta matriz e medindo cerca de 13 $\mathrm{cm}$ de comprimento e $5 \mathrm{~mm}$ de diâmetro, com quatro a cinco gemas.

Os tratos culturais foram realizados a cada 45 dias. $\mathrm{O}$ controle fitossanitário, com o fungicida Dacobre ${ }^{\circledR}$, na dosagem $7 \mathrm{~g} / 20 \mathrm{~L}$, e a fertilização em cobertura, com ureia, na dosagem $2000 \mathrm{mg} \mathrm{dm}^{-3}$. O controle das ervas daninhas foi realizado manualmente, sempre que necessário, deixandose as plantas livres das invasoras. A retirada dos brotos abaixo dos locais de enxertia foi realizada por ocasião de seu surgimento.

O delineamento experimental utilizado foi o de blocos casualizados, com cinco tratamentos (tipos de enxertia) e sete repetições. Cada parcela foi composta por 14 mudas, num total de 98 mudas por tratamento. Os tipos de enxertia foram: garfagem no topo em fenda cheia, garfagem no topo à inglesa, simples, garfagem no topo à inglesa, complicada, garfagem em fenda lateral e borbulhia em placa.

Foram avaliadas, aos 150 dias após a realização da enxertia, as variáveis: percentagem de pegamento dos enxertos, comprimento da parte aérea $(\mathrm{cm})$, comprimento do sistema radicular $(\mathrm{cm})$, comprimento de ramos $(\mathrm{cm})$, número de folhas, número de ramos, diâmetro do colo (mm), matéria seca da parte aérea (g/muda), matéria seca do sistema radicular (g/muda), matéria seca total (g/muda).

Os resultados obtidos foram submetidos à análise de variância e as médias dos dados foram comparadas pelo teste de Tukey, a 5\%, conforme recomendações de Gomes (2000). A análise foi realizada pelo programa computacional Sistema para Análise de Variância-SISVAR (Ferreira, 2000). 
Os índices de pegamento dos enxertos foram submetidos à transformação angular do $\operatorname{arcsen} \sqrt{\mathbf{x}} / 100 \mathrm{e}$, os dados de número de ramos, em $\sqrt{\mathbf{x}}+0,5$, conforme recomendações de Steel \& Torrie (1980). Para fins da realização da estatística, o tratamento de borbulha de placa foi desconsiderado, tendo em vista que apresentou índice zero de pegamento.

\section{RESULTADOS E DISCUSSÃO}

Os métodos enxertia tipo garfagem no topo em fenda cheia (FC), à inglesa, simples (IS), à inglesa, complicada (IC) e garfagem lateral (GL) apresentaram, a p <0,01, diferenças significativas em termos de percentagem de pegamento, número de ramos, comprimento da parte aérea, número de folhas, diâmetro de caule e massa seca do sistema radicular. Já para comprimento do sistema radicular, comprimento de ramo, massa seca da parte aérea e massa seca total, não foram verificadas diferenças significativas a $\mathrm{p}<0,05$ (Tabela 1). Por outro lado, foi observada a inviabilidade da enxertia de mudas de tamarindeiro por borbulhia de placa (BP), a qual apresentou índice zero de pegamento.

Os índices de percentagem de pegamento referentes aos métodos de enxertia são apresentados na Figura 1. A maior percentagem de pegamento foi observada quando se utilizou o método de garfagem no topo em fenda cheia $(43,81 \%)$. O método, porém, só apresentou diferenças significativas a $\mathrm{p}<0,01$, em relação ao método de garfagem em fenda lateral $(25,37 \%)$.

Esses resultados corroboram os de Ramirez et al. (1987), que compararam métodos de enxertia em tamarindeiro, em Piura, no Peru, e verificaram que a enxertia à inglesa simples e à inglesa em fenda dupla atingiram os maiores percentuais de pegamento: 61,3 e $65,3 \%$, respectivamente; enquanto a enxertia por borbulhia apresentou resultado de $9,3 \%$.

Em outras frutíferas esses tipos de enxertias proporcionaram maiores percentuais de pegamento. Souza et al. (2002) obtiveram, em cajazeira, maior percentual de pegamento (82\%), com o método de garfagem em fenda cheia, tendo este diferido estatisticamente da garfagem em fenda lateral, que teve $78 \%$ de pegamento. Araújo et al., (2002) e Bezerra et al. (1999) verificaram que a garfagem em fenda cheia e à inglesa simples apresentaram os maiores índices médios de pegamento em umbuzeiro e pitangueira, respectivamente. Pereira et al., (2002a) e Pereira et al., (2002b) avaliaram métodos de enxertia em mudas de mangabeira e pequizeiro, respectivamente; e observaram inviabilidade da enxertia por borbulhia de escudo com lenho, que apresentou índice zero de pegamento. Esses trabalhos ratificam os resultados encontrados neste estudo, no qual, os métodos de garfagem apresentam maior viabilidade para produção de mudas de tamarindeiro, quando comparados com o método de borbulhia.

Hartmann et al. (2002) evidenciam que ocorrem diferenças entre espécies e cultivares quanto ao pegamento, nos diversos métodos de enxertia, e que a variação está relacionada com a habilidade de produzir calo a partir de parênquima, essencial para o sucesso da união.

Essas diferenças entre os métodos de enxertia podem estar relacionadas com os propágulos, já que os garfos possuem maior quantidade de reservas (carboidratos) do que a borbulha, o que auxilia a cicatrização e brotação do enxerto (Celant et al., 2010).

Na Figura 2, são apresentados os valores para o número de ramificações. O maior número de ramificações foi obtido no método de garfagem no topo à inglesa, simples $(2,54)$, e o método da garfagem em fenda lateral apresentou a menor média $(1,87)$; esses métodos, no entanto, não diferiram significativamente da garfagem no topo à inglesa, complicada, e da garfagem no topo em fenda cheia.

Em macieira, Simões \& Carvalho (2006), verificou que o método de enxertia por garfagem à inglesa complicada apresentou maior percentagem de brotação que o da borbulhia lenhosa, porém não diferiram significativamente quando aplicados à garfagem de topo e à garfagem de meia fenda esvaziada. Por outro lado, Gomes et al. (2010), trabalhando a cultura do cajuí, verificaram que, entre as garfagens, a enxertia à inglesa, simples, apresentou o mais baixo núme-

Tabela 1: Quadrados médios da análise de variância para percentagem de pegamento (\% pegamento); comprimento da parte aérea (CPA); comprimento de sistema radicular (CSR); comprimento de ramo (CRM); número de folhas (NF); número de ramo (NR); diâmetro de caule (DC); massa seca da parte aérea (MSPA); massa seca do sistema radicular (MSSR) e massa seca total (MST) de mudas enxertadas de tamarindeiro. UFERSA, Mossoró, RN, 2010

\begin{tabular}{|c|c|c|c|c|c|c|c|c|c|c|c|}
\hline $\begin{array}{l}\text { Fonte de } \\
\text { Variação }\end{array}$ & G. L. & $\begin{array}{c}\% \\
\text { pegamento }\end{array}$ & CPA & CSR & CRM & NF & NR & DC & MSPA & MSSR & MST \\
\hline Métodos & 3 & $1790,22 * *$ & $713.80^{* *}$ & $46.91 \mathrm{~ns}$ & $86.03 \mathrm{~ns}$ & $2958.57 * *$ & $0,54 * *$ & $7,89 * *$ & $15,79 \mathrm{~ns}$ & $127,44 * *$ & $74,83 \mathrm{~ns}$ \\
\hline Bloco & 6 & $518,99 * *$ & $255.34 \mathrm{~ns}$ & $43.57 \mathrm{~ns}$ & $66.58 \mathrm{~ns}$ & $769.20 \mathrm{~ns}$ & $0,03 \mathrm{~ns}$ & $2,08 \mathrm{~ns}$ & $45,61 \mathrm{~ns}$ & $8,55 \mathrm{~ns}$ & $89,44 \mathrm{~ns}$ \\
\hline Erro & 18 & 140,56 & 149.87 & 38.66 & 46.58 & 481.93 & 0,09 & 1,55 & 24,63 & 8,19 & 50,40 \\
\hline Total & 27 & & & & & & & & & & \\
\hline C.V.(\%) & - & 17,37 & 18,10 & 13,86 & 27,72 & 37,39 & 13,56 & 15,11 & 35,46 & 36,47 & 32,51 \\
\hline
\end{tabular}

ns - não significativo; $* *$ - significativo a $\mathrm{p}<0,01$ por meio do teste $\mathrm{F}$ 
ro de estacas brotadas e de sobrevivência dos enxertos, contrariando os resultados encontrados neste estudo. Souza et al. (2010) não encontraram diferença significativa para o número de ramos entre os métodos de enxertia em cajazeira. No entanto, o método de enxertia à inglesa, simples, apresenta melhor desempenho, tanto no número de pegamentos dos brotos como no desenvolvimento da planta enxertada.

Celant et al. (2010) verificaram que a percentagem de brotação média para o método de garfagem proporcionou incremento de $71,8 \%$ de brotação dos enxertos, em comparação com a média da enxertia por borbulhia, avaliada em três períodos. Porém, Araújo et al. (2003) verificaram que, em mangabeira, a borbulhia de placa em janela aberta apresentou os melhores resultados, no tocante ao pegamento e à brotação de gemas.

O resultado para o número de ramos encontrados confirma, neste trabalho, a boa soldadura dos enxertos, reafirmando os resultados para as percentagens de pegamento encontradas, tendo em vista que a intensa atividade cambial e a disponibilidade de reservas do material propagado poderão ter favorecido tanto o processo de ligação cambial quanto o desenvolvimento das brotações.

Com relação ao comprimento dos ramos (Tabela 1), não foi verificada diferença significativa a 5\%; observou-se, no entanto, que o método de garfagem no topo em fenda cheia apresentou o maior valor médio $(29,01 \mathrm{~cm})$, seguido dos métodos de enxertia à inglesa simples $(25,76 \mathrm{~cm})$ e à inglesa complicada $(22,53 \mathrm{~cm})$, para o comprimento de ramo. Almeida (2009), estudando os métodos de enxertia de atemoia em espécies de Rollinia, verificou que os portaenxertos exercem influência na escolha do método de enxertia, observando que o método fenda lateral conferiu o maior comprimento de ramo sobre o porta-enxerto araticum-de-terra-fria e, em biriba, o método de enxertia que induziu maior comprimento de ramo foi a enxertia à inglesa simples. Souza et al. (2010) verificaram diferença significativa entre as modalidades de enxertia, quanto ao comprimento dos ramos; com a enxertia à inglesa, simples, apresentando comprimento maior que o dos métodos de garfagem em fenda cheia e garfagem em fenda lateral, que não diferiram entre si.

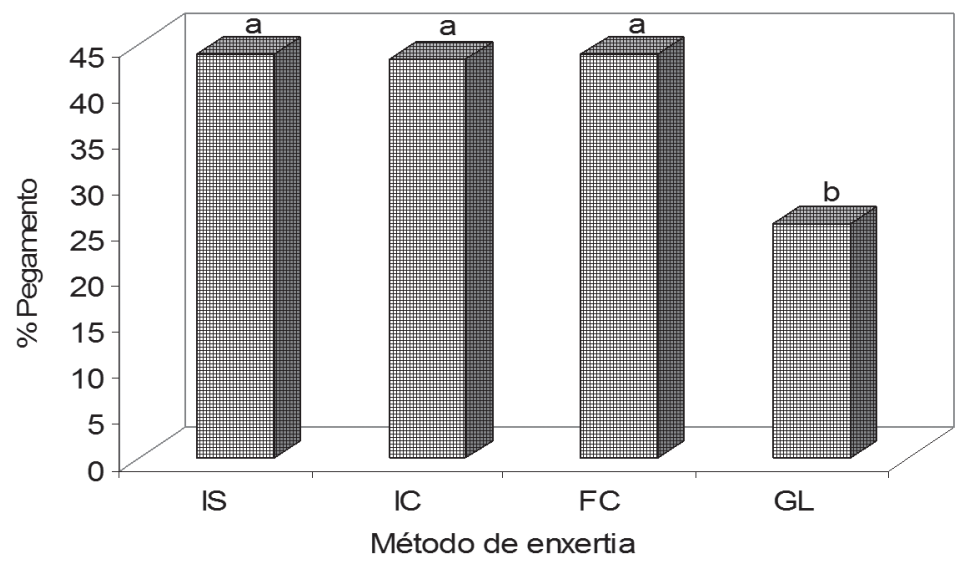

Figura 1: Percentagem de pegamento (\% Pegamento), em função dos métodos de enxertia à inglesa, simples (IS), à inglesa, complicada (IC), fenda cheia (FC) e garfagem lateral (GL), na produção de mudas enxertadas de tamarindeiro. Mossoró, RN, 2010.

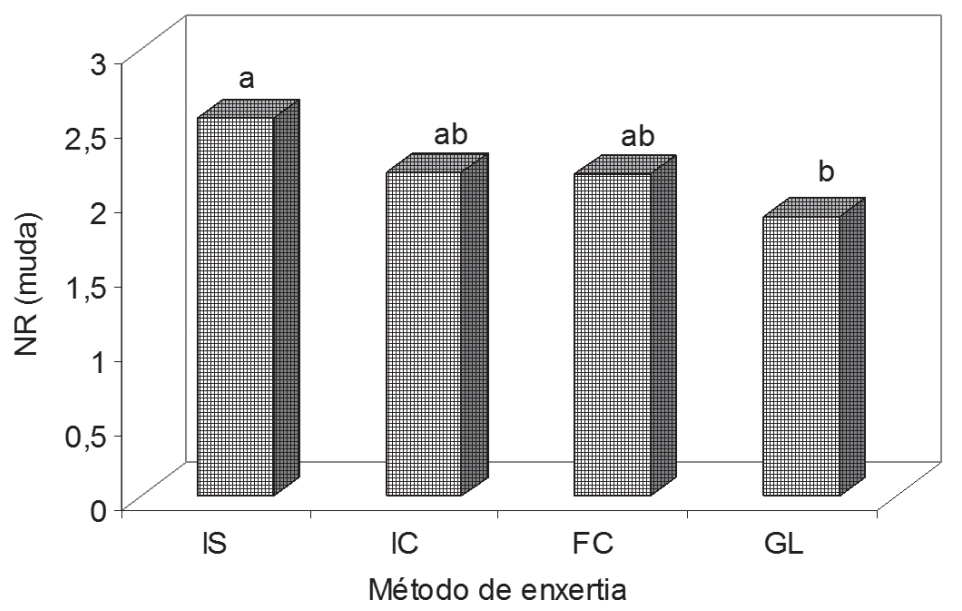

Figura 2: Número de ramos por muda (NR), em função dos métodos de enxertia à inglesa, simples (IS), à inglesa complicada (IC), fenda cheia (FC) e garfagem lateral (GL), na produção de mudas enxertadas de tamarindeiro. Mossoró, RN, 2010. 
Observa-se maior crescimento da parte aérea de mudas quando realizada a enxertia pelo método fenda cheia, que apresentou uma altura média de 77,00 cm (Figura 3); não foram observadas, entretanto, diferenças significativas quando se comparou esse método com os métodos de enxertia à inglesa, simples, e à inglesa, complicada, que apresentaram valores médios de 67,63 e 72,28 cm, respectivamente. O método de garfagem lateral, por outro lado, diferiu significativamente, apresentando os menores comprimentos: $53,61 \mathrm{~cm}$.

Estes resultados confirmam os encontrados por Vieira (2007), que verificou que o comprimento da parte aérea de mudas de cupuaçuzeiro, quando realizadas as enxertias pelos métodos de garfagem no topo em fenda cheia e garfagem à inglesa simples não apresentaram diferenças estatísticas entre si, embora as médias para a garfagem no topo em fenda cheia tenham sido ligeiramente superiores.

Reis et al. (2010) verificaram um crescimento linear para a altura de mudas de umbuzeiro, em estudo que avaliou estádios de desenvolvimento de mudas de umbuzeiros propagadas por enxertia em fenda cheia. Os resultados desses trabalhos, encontrados na literatura, ratificam os verificados neste trabalho, no qual se constatou que os métodos de garfagem apresentaram diferenças entre si, tendo-se destacado entre eles o método garfagem em fenda cheia.

O método garfagem em fenda lateral destacou-se por apresentar menor número médio de folhas $(28,29)$, o que o distinguiu dos demais métodos realizados (Figura 4). O maior número médio de folhas foi verificado nos métodos de enxertia em fenda cheia $(72,71)$, à inglesa, complicada $(69,29)$ e à inglesa, simples $(64,57)$, respectivamente. Esses métodos não apresentaram diferenças significativas entre si a p $<0,01$.

Os resultados do número de folhas em função do método de enxertia estão de acordo com os encontrados por Souza et al. (2007), para a cultura da videira, para a qual o método que se destacou foi a enxertia de fenda cheia. Os resultados, por outro lado, divergem do resultado encontrado por Almeida (2009), que verificou que o método de enxertia em fenda lateral proporcionou maior número inicial de folhas.

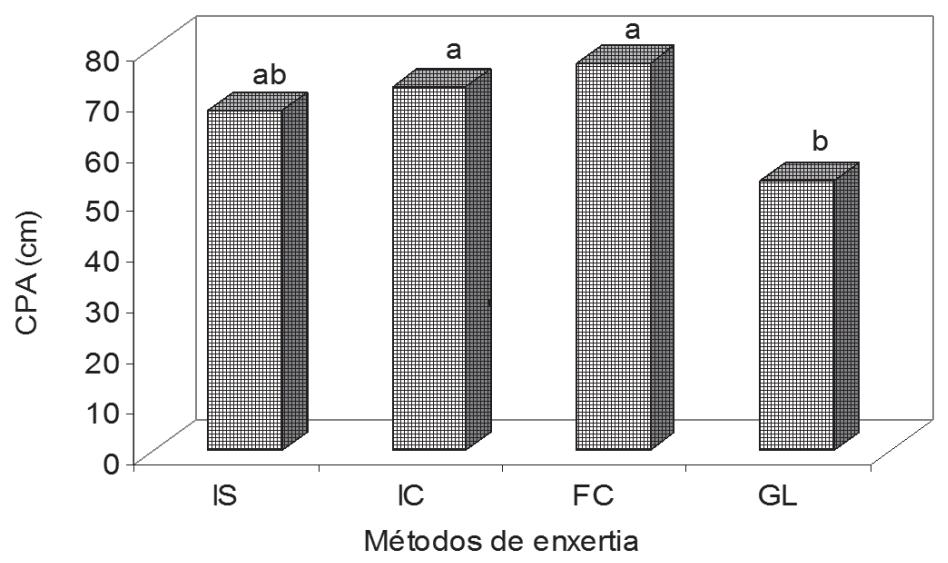

Figura 3: Comprimento da parte aérea (CPA), em função dos métodos de enxertia à inglesa, simples (IS), à inglesa, complicada (IC), fenda cheia (FC) e garfagem lateral (GL), na produção de mudas enxertadas de tamarindeiro. Mossoró, RN, 2010.

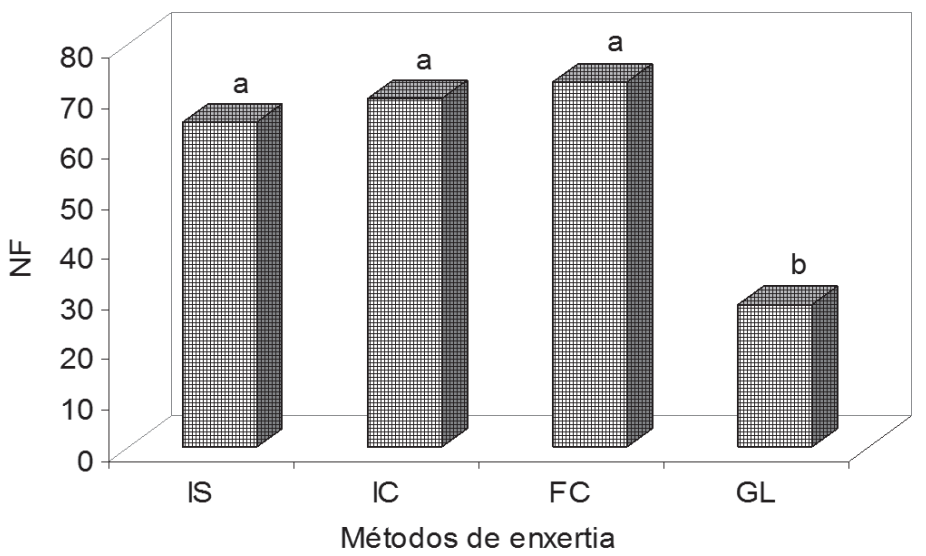

Figura 4: Número de folhas (NF), em função dos métodos de enxertia à inglesa, simples (IS), à inglesa, complicada (IC), fenda cheia (FC) e garfagem lateral (GL), na produção de mudas enxertadas de tamarindeiro. Mossoró, RN, 2010. 
O diâmetro de caule é a característica mais marcante para determinar se a muda está em condições de ser enxertada. Neste trabalho, o maior diâmetro de caule foi verificado no método de garfagem em fenda lateral, que não diferiu significativamente do método de enxertia à inglesa, complicada, que, entretanto, não diferiu dos métodos de garfagem no topo à inglesa, simples, e garfagem no topo em fenda cheia (Figura 5).

Segundo Franzon et al. (2008), em plantas lenhosas, à medida que o diâmetro do tronco aumenta, maior é o estado de lignificação e maior é a dificuldade de cicatrização e de união entre enxerto e porta-enxerto, fator que pode ser a explicação para a menor percentagem de pegamento no método de garfagem lateral, encontrada nesse estudo. $\mathrm{O}$ método de garfagem, à inglesa, complicada, por outro lado, alcançou resultados satisfatórios com relação a essas variáveis, decorrentes da maior área de contato entre o enxerto e o porta-enxerto.

Gomes et al. (2010) verificaram, trabalhando com cajuí, que a característica diâmetro do porta-enxerto apresenta diferença estatística entre todos os tipos de enxertia, sen- do que o tipo fenda cheia apresentou maiores valores, resultado que contraria os obtidos, neste estudo, para a cultura do tamarindeiro.

Para os métodos de enxertia, em relação à massa seca do sistema radicular, o método de garfagem em fenda lateral superou os demais métodos (Figura 6), resultados estes contrariados por Pio et al. (2010), que verificaram que a massa seca do cultivar de pêra Seleta apresentou melhores resultados, quando enxertada pelo método de garfagem em fenda cheia, em comparação com a borbulhia de placa.

A massa seca da parte aérea e a massa seca total não variaram significativamente, a $\mathrm{p}<0,05$, em função dos métodos de enxertia. No entanto, os valores médios dessa variável, quando realizada a enxertia do tipo fenda cheia, apresentaram ligeira superioridade sobre os dos demais. Resultados semelhantes foram verificados por Vieira (2007) para o cupuaçuzeiro para o qual se observaram as maiores médias para massa seca quando realizada a garfagem no topo em fenda cheia, que não apresentou diferença estatística em relação à garfagem à inglesa.

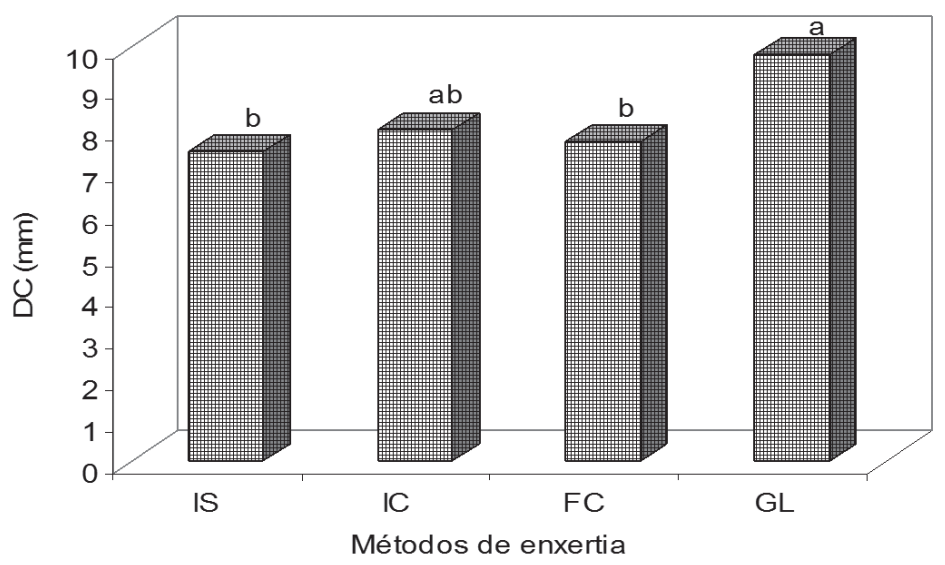

Figura 5: Diâmetro de caule (DC), em função dos métodos de enxertia à inglesa, simples (IS), à inglesa, complicada (IC), fenda cheia (FC) e garfagem lateral (GL), na produção de mudas enxertadas de tamarindeiro. Mossoró, RN, 2010.

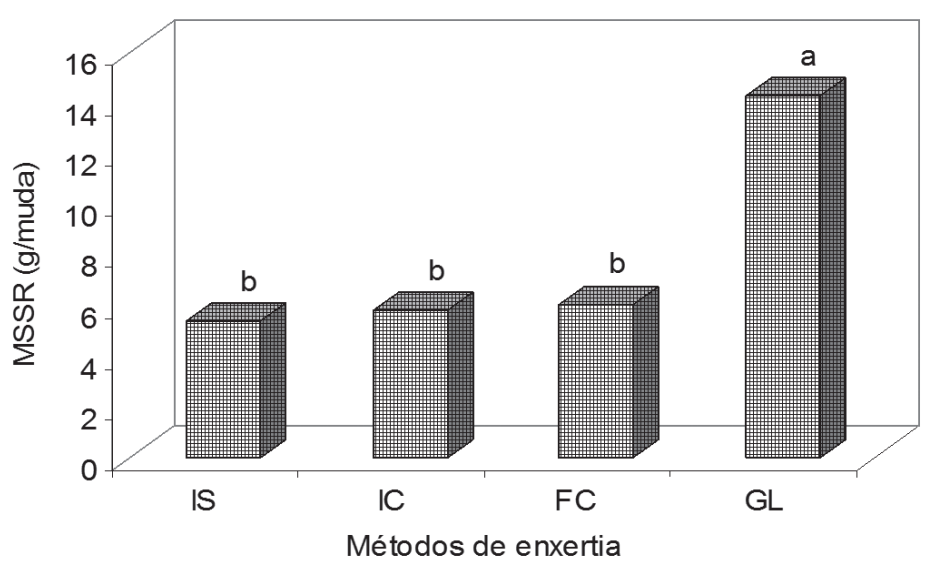

Figura 6: Massa seca do sistema radicular (MSSR), em função dos métodos de enxertia à inglesa, simples (IS), à inglesa, complicada (IC), fenda cheia (FC) e garfagem lateral (GL), na produção de mudas enxertadas de tamarindeiro. Mossoró, RN, 2010. 


\section{CONCLUSÕES}

Os métodos garfagem no topo em fenda cheia, garfagem no topo à inglesa, complicada, e garfagem no topo à inglesa, simples, foram os melhores, obtidos nesta pesquisa, para a produção de mudas de tamarindeiro.

\section{REFERÊNCIAS}

Almeida LFP (2009) Propagação por enxertia de araticum (Annona crassiflora Mart.) e atemoia (Annona squamosa L. X Annona cherimola Mill.) em diferentes portaenxertos de Annonaceae. Dissertação de Mestrado. Universidade de Brasília, Brasília. 109p.

Araújo FP \& Castro Neto MT (2002) Influência de fatores fisiológicos de plantas-matrizes e de épocas do ano no pegamento de diferentes métodos de enxertia do umbuzeiro. Revista Brasileira de Fruticultura, 24:752-755.

Araújo IA, Franco CFO, Santos ES \& Neto MB (2003) Influência de Tipo e Época de Enxertia na Propagação da Mangabeira (Hancornia speciosa Gomes). In: Simpósio brasileiro sobre a cultura da mangaba, Aracaju. Anais, Embrapa Semiárido. CD-ROM.

Bezerra JEF, Lederman IE, Freitas EV \& Santos VF (1999) Método de enxertia e idade de portaenxerto na propagação da pitangueira (Eugenia uniflora L.). Revista Brasileira de Fruticultura, 21:262-265.

Celant VM, Pio R, Chagas EA, Alvarenga AA, Dalastra IM \& Campagnolo MA (2010) Armazenamento a frio de ramos porta borbulhas e métodos de enxertia de cultivares de marmeleiro. Disponível em: <http://www.scielo.br/pdf/cr/v40n1/ a392cr2240.pdf>. Acessado em: 07 de julho de 2013

El-Siddig K, Gunasena HPM, Prasad BA, Pushpakumara DKNG, Ramana KVR, Vijayanand P \& Williams JT (2006) Tamarind (Tamaridus indica L.). Southampton, International Centre for Underutilized Crops. 188p.

Ferreira DF (2000) Análise estatística por meio do SISVAR (Sistema para Análise de Variância) para Windows versão 4.0. In: $45^{\mathrm{a}}$ Reunião anual da região brasileira da sociedade internacional de biometria, São Carlos. Anais, UFSCar. p.255-258.

Franzon RC, Gonçalves RS, Antunes LEC \& Raseira MCB (2008) Propagação da pitangueira através da enxertia de garfagem. Revista Brasileira de Fruticultura, 30:488-491.

Gomes FP (2000) Curso de estatística experimental. 14 ${ }^{\mathrm{a}}$ ed. Piracicaba, USP. $477 \mathrm{p}$.

Gomes JG, Oliveira NCC, Lopes PSN \& Carneiro PAP (2010) Enxertia do cajuí (Anacardium othonianum Rizz.) no Norte de Minas Gerais. In: $21^{\circ}$ Congresso brasileiro de fruticultura, Natal. Anais, SBF. CD-ROM.

Gurjão KC de O (2006) Desenvolvimento, Armazenamento e Secagem de Tamarindo (Tamarindus indica L.). Tese de Doutorado. Universidade Federal da Paraíba, Areia. 139p.

Hartmann HT, Kester DE, Davies Junior FT \& Geneve RL (2002) Plant propagation: principles and practices. $7^{\mathrm{a}}$ ed. New Jersey, Prentice Hall. 880p.

Komutarin T, Azadi S, Butterworth L, Keil D, Chitsomboon B, Suttajit M \& Meade BJ (2004) Extract of the seed coat of Tamarindus indica inhibits nitric oxide production by murine macrophages in vitro and in vivo. Food and Chemical Toxicology, 42:649-658.

Pereira AV, Pereira EBC, Fialho JF, Junqueira NTV \& Gomes AC (2002a) Avaliação de Métodos de Enxertia em Mudas de Pequizeiro. Planaltina, Embrapa Cerrados. 15p. (Boletim de Pesquisa e Desenvolvimento, 51).
Pereira EBC, Pereira AV, Charchar MJD, Pacheco AR, Junqueira NTV \& Fialho JF (2002b) Avaliação de Métodos de Enxertia em Mudas de Mangabeira. Planaltina, Embrapa Cerrados. 16p. (Boletim de Pesquisa e Desenvolvimento, 50).

Pio R, Seifert KE, Celant VM, Chagas EA, Campagnolo MA \& Dalastra IM (2010) Produção de mudas de Pêra por dupla enxertia em interenxertos de marmeleiro utilizando o portaenxerto 'japonês'. In: $21^{\mathrm{a}}$ Congresso Brasileiro de Fruticultura, Natal. Anais, SBF. CD-ROM.

Ramirez L, Montesinos A \& Guzman L (1987) Uma comparação de métodos de enxertia na propagação assexuada de tamarindo (Tamarindus indica L.), em Piura, Peru. Disponível em: <http:/ /agris.fao.org/agris-earch/search/display.do?f=1987/XL/ XL87003.xml;XL8700013>. Acessado em: 25 de outubro de 2010.

Reis RV, Fonseca N, Ledo CAS, Gonçalves LSA, Partelli FL, Silva MGM \& Santos EA (2010) Estádios de desenvolvimento de mudas de umbuzeiros propagadas por enxertia. Ciência Rural, 40:787-792.

SEAGRI - Secretaria de Agricultura, Irrigação e Reforma Agrária (2010) A cultura do tamarindeiro. Disponível em: <http:// www.seagri.ba.gov.br/Tamarindo.htm>. Acessado em: 26 de outubro de 2010.

Simões F \& Carvalho RIN (2006) Avaliação de diferentes métodos de sobre-enxertia na substituição da cultivar de macieira (Malus domestica Borkh.) Gala por Princesa. Acta Scientia Agronômica, 28:493-498.

Sousa DMM, Bruno R de LA, Dornelas CSM, Alves EU, Andrade AP de, Nascimento LC (2010) Caracterização morfológica de frutos e sementes e desenvolvimento pós-seminal de Tamarindus indica L. - Leguminosae: Caesalpinioideae. Revista Árvore, 34:1009-1015.

Souza EP, Mendonça RMN, Silva SM, Estrela MA, Souza AP \& Silva GC (2010) Enxertia da cajazeira. Revista Brasileira de Fruticultura. 32:316-320.

Souza FX, Inneco R \& Rosseti AG (2002) Influência de portaenxerto e de método de enxertia no pegamento de enxertos de cajazeira. Revista Agrotrópica, 14:85-90.

Souza J, Botelho RV \& Schreider E (2007) Avaliação dos Métodos e Épocas de Enxertia em Videira 'Niagara Rosada' (Vitis labrusca) sobre o portaenxerto '43-43' (V. Vinifera XV. rotundifolia). In: Encontro Paranaense de Fruticultura, Paraná. Anais, Unicentro. $176 \mathrm{p}$.

Steel RGD \& Torrie JH (1980) Principles and procedures of statistics. New York, McGraw-Hill. 633 p.

Suralkar AA, Rodge KN, Kamble RD \& Maske KS (2012) Evaluation of anti-inflammatory and analgesic activities of Tamarindus indica seeds. Intern. Journal of Pharmaceutical Sciences and Drug Research, 4:213-217.

Vieira ES (2007) Propagação vegetativa do cupuaçuzeiro por enxertia e estaquia. Dissertação de Mestrado. Universidade Federal do Recôncavo da Bahia, Cruz das Almas. 45p. 